\title{
El potencial de los museos en la conservación del patrimonio cultural
}

\author{
Melissa Regina Campos Solórzano \\ Antropóloga. \\ Museo Universitario de Antropología, MUA \\ UTEC
}

El artículo es el resultado de una reflexión que parte de la investigación titulada "Propuesta para un museo sin muros para la reactivación de la memoria urbana en la calle Arce", que buscó formular una propuesta museológica de exposición en la vía pública para crear un vínculo real entre la comunidad y el Patrimonio Cultural del Centro Histórico de San Salvador, iniciada en 2011, a partir de los estudios en Maestría en Patrimonio Cultural y Territorio realizados en la Pontificia Universidad Javeriana de Colombia, tomando como caso de estudio el proceso de reordenamiento de la calle Arce en la ciudad de San Salvador, El Salvador, Centroamérica.

\section{Introducción.}

Mucho se ha escrito sobre patrimonio cultural en El Salvador, sin embargo, muy poco sobre éste como la conjunción de factores de identidad, emocionales, históricos, espirituales, sociales, entre otros que, en conjunto, van más allá de la admiración hacia la monumentalidad y la continuidad de lo antiguo, principalmente de inmuebles arquitectónicos y de artefactos prehispánicos.

Abordar el estudio del Patrimonio Cultural, implica tomar en cuenta toda una complejidad de retos más allá de considerar lo folclórico o monumental; por ello, me propongo explorar una alternativa para reconocer el patrimonio como una construcción social desde el presente, fuera de la forma rígida y tradicional de reconocimiento ligado a las hegemónicas valoraciones eurocéntricas, con el propósito de avanzar hacia la consolidación de una mirada incluyente, en la cual, el patrimonio se articula —necesariamente— con su contexto.

Por lo general, el patrimonio se clasifica en tangible e intangible según se relacione con un objeto físico o con un producto inmaterial, como una obra intelectual o determinados usos y costumbres. Ya se trate de uno u otro, el 
patrimonio, desde un punto de vista conceptual, se ubica siempre en una esfera axiológica, es decir que un objeto adquiere el estatuto de patrimonio en función de los valores que le atribuye una comunidad determinada. En este sentido, las estrategias de conservación del patrimonio están orientadas a "otorgar valor" a los elementos que han sido elegidos. ${ }^{1}$

Para empezar con un breve enfrentamiento conceptual que nos vaya aclarando el problema, se puede citar la definición de patrimonio aportada hace casi dos décadas por la UNESCO, organismo rector en la materia:

El patrimonio cultural de un pueblo comprende las obras de sus artistas, arquitectos, músicos, escritores y sabios, así como las creaciones anónimas surgidas del alma popular, el conjunto de valores que dan sentido a la vida, es decir, las obras materiales y no materiales que expresan la creatividad de un pueblo, la lengua, los ritos, las creencias, los lugares y monumentos históricos, la literatura, las obras de arte, y los archivos y bibliotecas. ${ }^{2}$

Sin embargo, parece que esta definición abarca tanto que dice poco, pero así suele ser cuando las reflexiones para determinar que un artefacto cultural es un bien cultural se dejan en manos de los intelectuales -los expertos- a razón que nos hemos acostumbrado a que los asuntos de importancia cultural queden en manos de cualquier persona eficazmente preparada en tratados culturales internacionales (en el mejor de los casos). Por ello, considero clave comenzar a clarificar qué entenderemos por Patrimonio Cultural mediante una aproximación alternativa a la de UNESCO que, como ya vimos, se reduce a bienes culturales con características de monumentalidad, historicidad, ritualidad, etc., que se entremezclan en una misma definición a manera de una receta clásica de salpicón cultural.

Por lo anterior, una aproximación alternativa a la definición de Patrimonio Cultural es útil en la medida que se pueda tener una idea más cercana del concepto como una construcción social, que no existe en la naturaleza, ni es una constante cultural, sino que, es producto de la inventiva de algunos que logra consensuarse en una pluralidad; lo que lo hace cambiante, dinámico y flexible según sean las circunstancias. De este modo, debería ser la misma

1. Al respecto, L. Oriad. Contra la ciudad-museo: el papel del comercio callejero para la conservación del patrimonio urbano de los barrios tradicionales. En: Apuntes 24 (2): 288-299. 2011.

2. Al respecto, D. Vidart. El rico patrimonio de los orientales. Montevideo: Banda Oriental. Disponible en: www.unesco.org/culture/heritage/intangible/html_sp/index_sp-shtm., pág 142. 2004. 
comunidad quien establezca el valor patrimonial de los bienes culturales en su territorio.

\section{La necesidad de repensar los museos en el siglo XXI.}

En El Salvador, la historia museológica comienza a finales del siglo XIX, en 1883, con la fundación del Museo Nacional de Antropología "Dr. David J. Guzmán", desde entonces, nuevos museos han sido creados desde los enfoques de la museología tradicional, que para la percepción de muchos, se trata de espacios elitistas, autoritarios y de puertas cerradas.

Usualmente, los contextos territoriales de los museos ${ }^{3}$ ayudan a fortalecer ese imaginario de espacios exclusivos y excluyentes, por ser lugares fuertemente custodiados, de emplazamiento monumental, con actividades -lastimosamente- exentas a las dinámicas sociales de la comunidad que los rodea y vistos como espacios estáticos y sacralizados; dicho de otro modo, parecieran ser espacios desvirtuados de lo que según el Concilio Internacional de Museos los define como espacios creados para el desarrollo de la sociedad y abiertos a todo público ${ }^{4}$

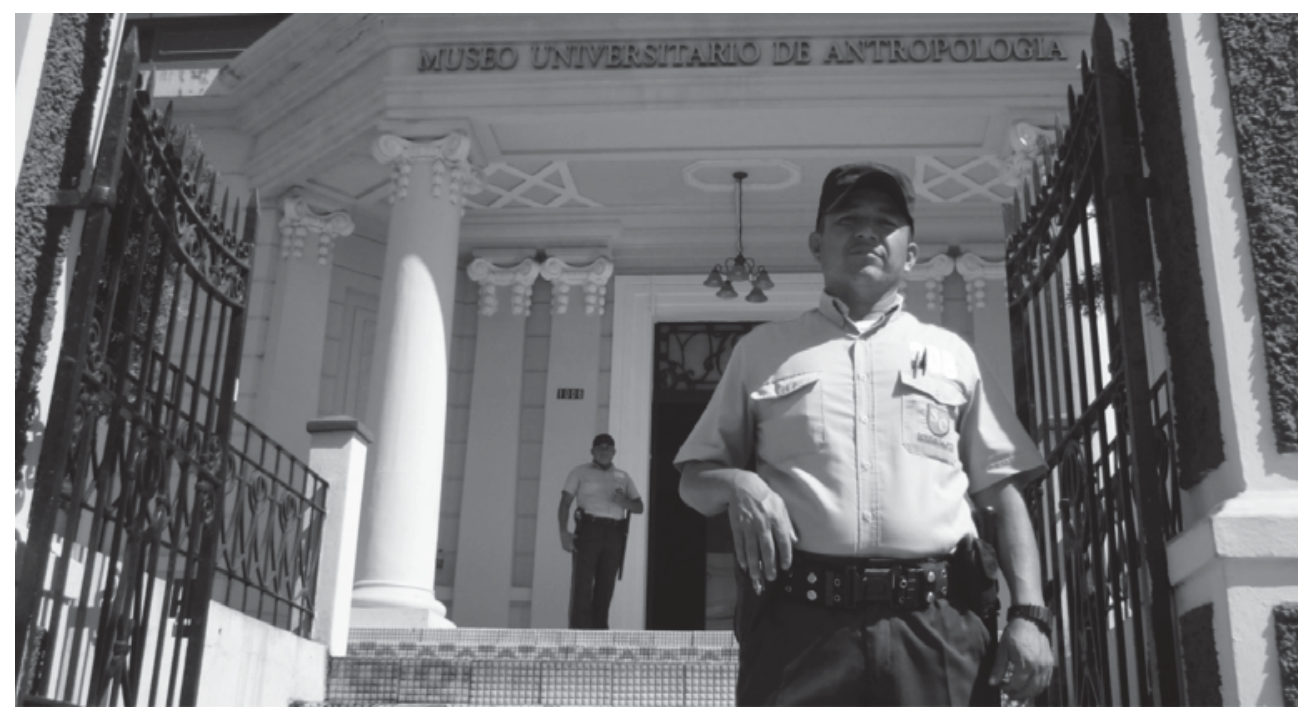

Equipo de seguridad en el MUA, edificio Anastasio Aquino, donde desde 1987 funcionó la Rectoría de la Universidad. Foto: Melissa Campos, 2013.

3. De aquí en adelante, me refiero a museos como emplazamientos urbanos 4. Al respecto, Timothy Ambrose y Paine, Crispin. Museum Basics. The heritage: care-preservationmanagment. Routledge 2da edición, New York. 2008. 
A razón de lo anterior, continuo y considero, que al igual que las formas de comunicación se trasforman en el tiempo adaptándose a las exigencias de la actualidad con las nuevas tecnologías, también es momento de reflexionar sobre la necesidad de reinterpretar los museos como espacios culturales vivos, que vayan más allá de las exposiciones permanentes y temporales organizadas hacia el interior de sus cedes, y que busquen un acercamiento verdadero de su institución museal con las comunidades que los rodean mediante la supresión virtual de los muros, para que más allá de afirmar en palabras que son espacios de puertas abiertas, literalmente lleven hacia su exterior las variantes de narrativas posibles, contenidos construidos idealmente en conjunto con las personas que habitan los entornos de los museos y cuya interacción sea compartida con la sociedad en exposiciones exhibidas en las vías públicas con el objetivo de avanzar en la apropiación del Patrimonio, mediante la puesta en práctica de los nuevos procesos de comunicación y diálogo, inmersos en las concepciones contemporáneas que incorporan los procesos museológicos modernos, es decir, se trata de replantear la manera de esbozar un nuevo paradigma para la valoración, significación e interpretación del patrimonio cultural.

\section{La museología como enlace del patrimonio y la comunidad.}

No cabe duda que una de las formas de apropiarse del territorio es mediante el conocimiento e identificación con el mismo; de ahí, que el museo pueda pensarse como un espacio para conseguir tal fin. Evidentemente, las formas y las funciones de los museos han variado sensiblemente en el curso de los siglos. Su contenido se ha diversificado al igual que su misión, su forma de funcionamiento y su administración.

La definición de museo más difundida y aceptada hasta hoy, sigue siendo la consignada desde $2007^{5}$ en los Estatutos del Consejo Internacional de Museos (ICOM):

El museo es una institución permanente, sin fines de lucro, al servicio de la sociedad y de su desarrollo, abierta al público que adquiere, conserva, estudia, expone y transmite el patrimonio material e inmaterial de la humanidad $y$ de su medio ambiente con fines de educación y deleite. ${ }^{6}$

\footnotetext{
5. Esta definición reemplaza a la establecida por el mismo Consejo en los Estatutos de 1974, diferenciándose de la anterior por incluir el componente del patrimonio inmaterial en ella.

6. Al respecto, ICOMOS. Declaración sobre la preservación del Espíritu de lugar, Quebéc. 2008.
}

REVISTA DE MUSEOLOGÍA KÓOT, 2013, AÑO 3, No 4, ISSN 2078-0664, ISSNE 2307-3942 
A esta definición tradicional se enfrenta el concepto de la nueva museología como una de las corrientes museológicas actuales más fuertes por asumir como propios los cambios del entorno de los museos, rompiendo con aquella concepción estática y permanente que a lo largo de la historia había caracterizado a la museología tradicional. Amparados bajo la nueva museología, los museos como recintos cerrados destinados a exponer, han roto sus muros, y en la actualidad cada vez se asiste más a la creación de museos fuera del museo $^{7}$. En palabras de Luis Alonso Fernández, la nueva museología:

ha variado al comprobarse la superación de pura e intangible entidad sacrosanta (el museo) para convertirse en instrumento de desarrollo y dinamización sociocultural al servicio de una sociedad abierta y democrática...

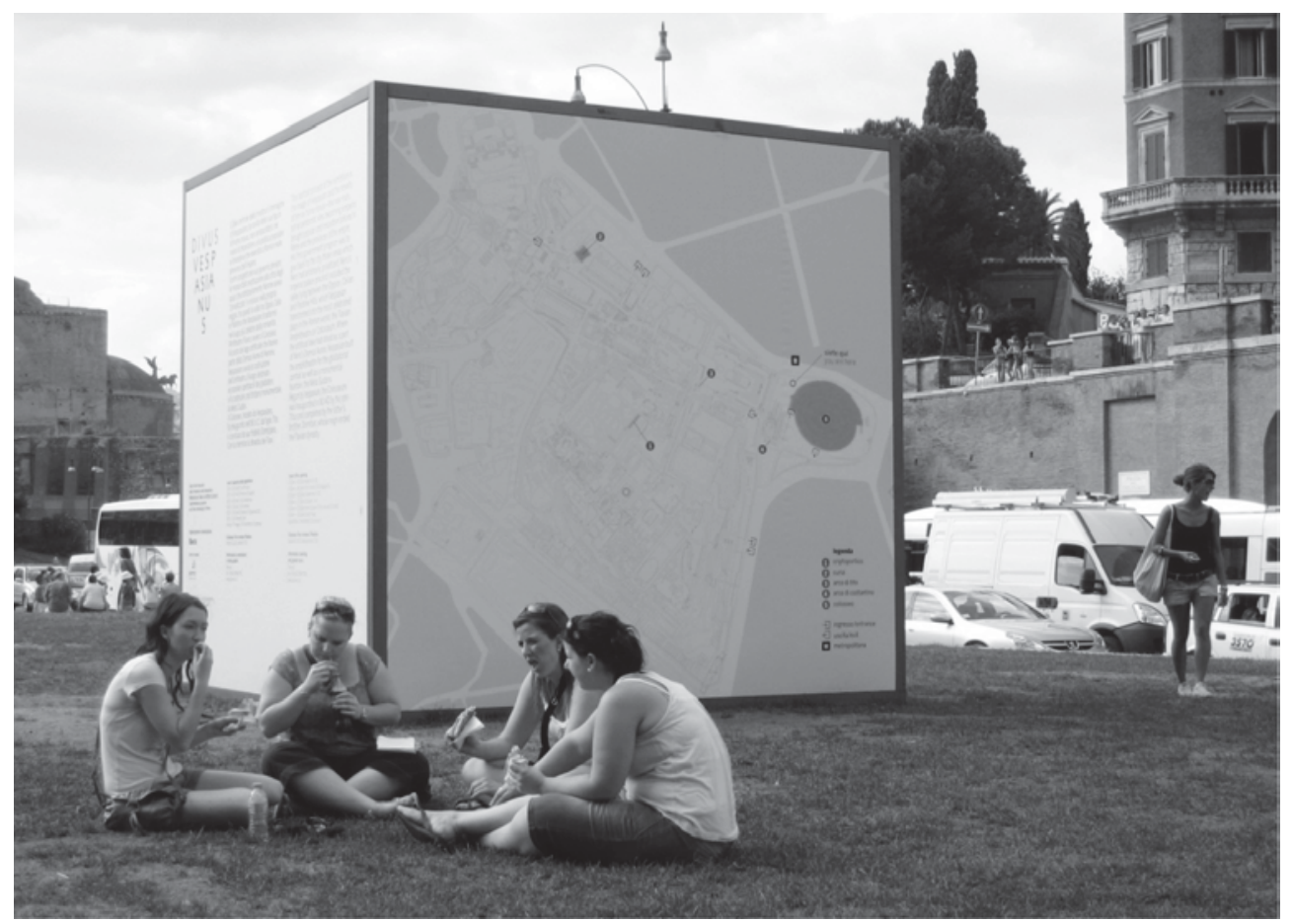

Los modelos de muebles museográficos deben adaptarse a cada circunstancia y contexto particular. La imagen muestra un modelo de divulgación del patrimonio al aire libre en la ciudad de Roma, Italia. Foto: Daniel Castro, 2012.

Además, ha venido desde una posición lejana e inaccesible al público no es-

7 Al respecto, Julia Barroso. El discurso museográfico y la comunicación del Patrimonio. Roser Calaf coord., Comunicación educativa del patrimonio: Referentes, modelos y ejemplos. Madrid: Trea. 2004. 8. Ibíd.

REVISTA DE MUSEOLOGÍA KÓOT, 2013, AÑO 3, No 4, ISSN 2078-0664, ISSNE 2307-3942 
pecializado a adquirir una concienciación de institución cultural al servicio de todos y utilizable por todos los miembros de una comunidad ${ }^{9}$.

En definitiva, la nueva museología ha sido impulsada por una evolución de apertura en la mentalidad de algunos museólogos, que a partir del previo cuestionamiento del museo y sus funciones patrimoniales en nuestra sociedad, han destacado que el museo debe trascender hacia un enfoque multidisciplinar donde el acento se sitúe en las relaciones entre el ser humano y su medio cultural; adicionalmente, la nueva museología establece que el museo ya no se debe dirigir a públicos indeterminados considerados en la museología tradicional como visitantes anónimos, sino que, debe tener su razón de ser en estar al servicio de una comunidad específica; además, en la museología tradicional, el museo es físicamente hablando un edificio, una casa o un espacio determinado que contiene y exhibe una colección de objetos, en cambio, la nueva museología resulta ser el territorio de su comunidad, donde la infraestructura museográfica se descentraliza, se fragmenta y convierte el territorio en el medio de apropiado para la divulgación de mensajes mediante exposiciones abiertas, al aire libre, es decir, se camina hacia un futuro con museo sin muros $^{10}$.

\section{Museos al servicio de quién...}

A finales del siglo XX, los esfuerzos por recuperar los Centros Históricos de ciudades en América Latina a través de proyectos de revitalización por parte de las municipalidades, han intentado limpiar las calles de todo aquello que obstruya la apreciación visual de los edificios que bordean los recorridos de los ejes urbanos.

Por lo anterior, el presente artículo intenta abordar de manera integral el estudio del Patrimonio usando las propuestas museológicas como medios de investigación y divulgación que busquen involucrar la voz de comunidad en la construcción de los contenidos curatoriales y compartida a través de las exposiciones.

9 Fernández, Luis. (1999). Introducción a la nueva museología. Madrid:Alianza. ICOMOS (2008) Declaración sobre la preservación del Espíritu de lugar, Quebéc.

10 Ibíd. 
Ahora bien, en este mundo agitado, en la que las urbes se caracterizan por ser espacios congestionados, caóticos, inseguros, el transurbar ${ }^{11}$ se ha relegado a los centros comerciales básicamente ${ }^{12}$, por lo cual, cada vez parece menos atractivo visitar los museos que muestran lo mismo y que no se renuevan a la velocidad que lo hacen las vitrinas de los comercios. Por ello, creo que los museos sin muros, pueden instigar a las personas en medio de las dinámicas cotidianas de desplazamientos a pie $^{13}$ a entablar un breve - pero certerodiálogo entre el patrimonio (la exposición) y la comunidad (el ser humano en movimiento).

La intención es incluir a las valoraciones patrimoniales los aspectos intangibles de la ciudad que, al final de cuentas, son los que dan vida los elementos físicos de la ciudad ${ }^{14}$ o lo que también podríamos llamar el Espíritu del lugar. ${ }^{15}$

Hasta ahora, las estrategias de conservación del patrimonio urbano han tenido como principal objetivo, aumentar el valor de la ciudad por medio de la mejora de los aspectos físicos de fachadas y el embellecimiento de espacios públicos, que evidencian un entendimiento de los valores patrimoniales, únicamente en relación con los aspectos tangibles. No discuto que la ciudad es un objeto complejo, compuesto de estructuras físicas, pero reitero que su valor viene dado en consonancia con las dinámicas sociales y económicas que interactúan con los espacios construidos. Ignorar este hecho, ha dado lugar a estrategias de conservación cosméticas que —en la realidad- ponen en riesgo la conservación de la esencia patrimonial de ciudad.

Por esta razón, creo importante considerar la expansión del centro de acción de los museos para ampliar las reflexiones en torno a los valores patrimoniales en las vías públicas de los contextos urbanos. Mediante la implementación de

\footnotetext{
11. Término usado por Francesco Careri en su libro Walkscapes, en el que se refiere a la lectura de la ciudad actual desde el punto de vista del errabundeo, como una especie de lectura de paisaje a partir del andar (a pie), haciendo una relación entre el recorrido y la arquitectura como construcción simbólica del territorio.

12. Me atrevo a decir que pocas personas cambiarían una salida a un centro comercial (o una sala de cine) por una visita a un museo tradicional.

13. con intención específica: hacer trámites, ir a la universidad, ir almorzar, etc.

14. Arquitectura histórica, los monumentos, el perfil de las calles, etc.

15. Traducción al español del antiguo concepto romano de Genius loci. Concepto desarrollado por Norberg Schulz (1980) y retomado en 2008 en la declaración de Quebec sobre la preservación del espíritu del lugar definido como: "el conjunto de los elementos materiales (sitios, paisajes, construcciones, objetos) e inmateriales (memorias, relatos, ritos, festivales, conocimientos), físicos y espirituales, que dan sentido, valor, emoción y misterio al lugar." (ICOMOS, 2008).
} 
museos sin muros, se busca - precisamente- que tanto quienes permanecen a diario en las calles, como aquellos transeúntes casuales, tengan un atractivo adicional en sus recorridos, de esta manera el museo puede contribuir a que la ciudad cumpla con su función primordial de ser el lugar de encuentros y del intercambio social por excelencia.

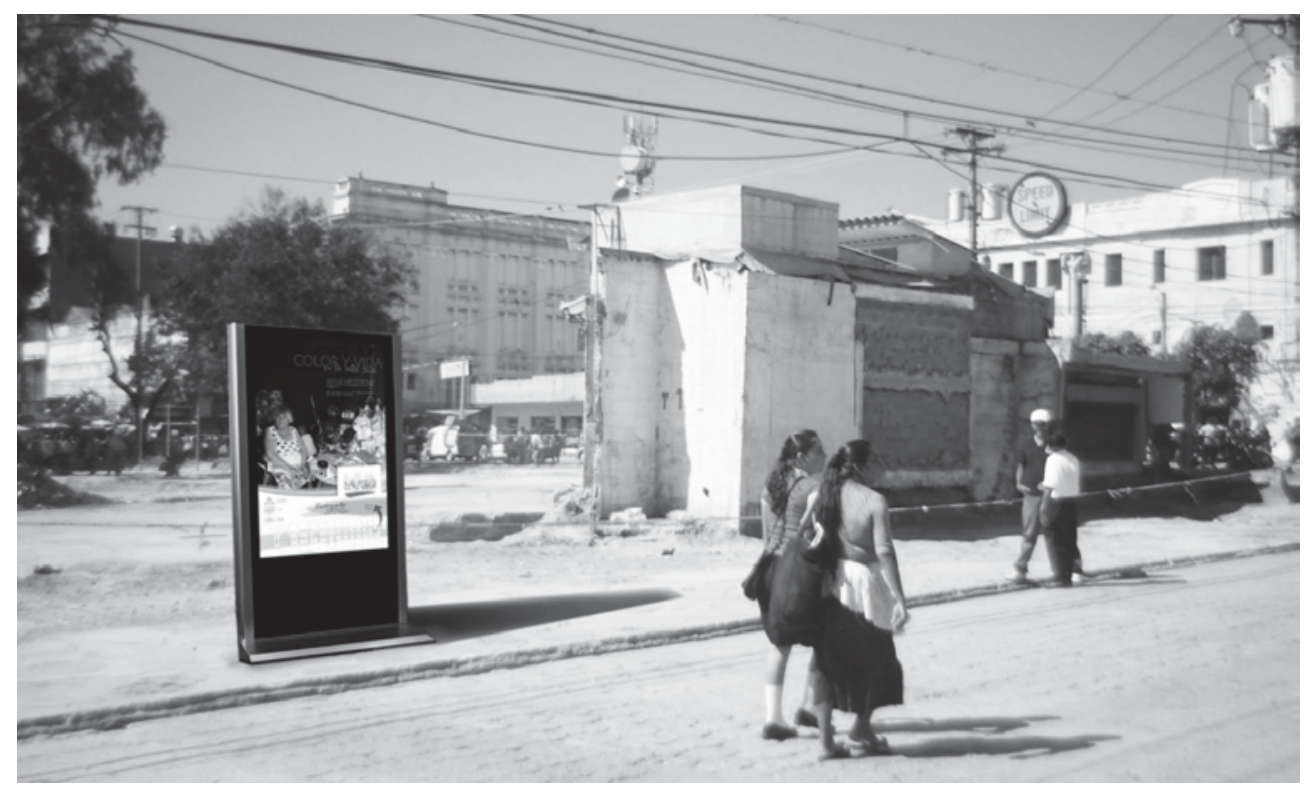

Propuesta de mueble de información urbana que comparte los testimonios de los vendedores que por más de tres décadas han ocupado las calles del Centro Histórico de San Salvador. Imagen fuente: LPG, 2012. Montaje: Melissa Campos.

En mi opinión, el comercio en las calles, es parte de ese funcionamiento e intercambio social de las ciudades, no obstante — para otros- esta actividad es usualmente asociada a valores negativos, ligados sobre todo a la informalidad, el desorden y a la pobreza. Si bien es cierto, cuando el comercio de ambulantes hace un uso desmedido de las calles, contribuye a destruir el entorno físico (o del paisaje si se quiere); pero esto debería llevarnos a plantear mecanismos de regulación que impidan la expansión anárquica de esta actividad, más que, al más claro desperdicio de esfuerzos ${ }^{16}-\mathrm{y}$ recursos- por la búsqueda de aceras asépticas de cualquier actividad (y de vendedores).

16. Un ejemplo claro de esto que describo es la reciente intervención de reordenamiento del Centro Histórico de San Salvador, en la cual se hicieron de lado las experiencias y testimonios de los vendedores callejeros, quienes a pesar de ser parte de las costumbres vivas de la ciudad, no son considerados bajo ningún ángulo como parte de su valor. 
De este modo, el presente artículo defiende la idea de que una verdadera estrategia de conservación del patrimonio urbano no debería bajo ninguna circunstancia, menospreciar el papel de las comunidades locales, cuyo valor ayuda a construir el sentido de identidad y el vínculo emocional con los lugares patrimoniales.

El reto consiste entonces, en adoptar propuestas innovadoras y dinámicas, basadas en la valoración significativa e integral del Patrimonio Cultural, de manera que pueda asegurarse su continuidad y vitalidad para las generaciones actuales y futuras. De hecho, cualquier lugar debería tener la capacidad de adaptar diferentes dinámicas a su entorno dentro de ciertos límites; de lo contrario, un lugar asignado para un solo propósito pronto se tornará obsoleto e inútil. Por ello, la idea es que mediante las formas modernas de comunicación y divulgación de museos, presente de forma sistemática las narrativas de la ciudad, de la calle y de su gente; lograrlo permitiría reactivar el vínculo real de la comunidad con su patrimonio, y de esta manera, sería la comunidad misma quien abogaría por que se conserven sus valores hacia el futuro.

\section{Conclusiones.}

Para nadie es ajeno que los modos de comunicación han cambiado al ritmo que lo exigen las sociedades contemporáneas; del mismo modo, debe empezarse a considerar cambios de actitud y de apertura para desarrollar una evolución en las formas de concepción museográficas aun estancadas en el pasado.

Con la convicción que los planteamientos de los museos sin muros como nueva propuesta museológica pueden llegar servir como medio para dar cumplimiento a los requisitos obligatorios que deben regir la interpretación del patrimonio ${ }^{17}$ :

- Estar dirigido al público general-comunidad del patrimonio,

- Ser parte de una actividad libre y voluntaria,

- Crear propuestas inspiradoras que lleguen al espíritu de los individuos,

- Estimular la participación activa de la comunidad,

- Mantener como meta la conservación del patrimonio mediante una forma de comunicación atractiva.

17. Al respecto, Hernández citando a Moralez en Francisco Hernández, Didáctica e interpretación del patrimonio. En Roser Calaf coord., Comunicación educativa del patrimonio: Referentes, modelos y ejemplos. Madrid: Trea. 2004. 
El énfasis radica en que se deben dejar atrás las concepciones tradicionales que ven en la comunidad únicamente el papel pasivo de receptor de información; y por el contrario, deberíamos avanzar hacia una autocritica que ponga sobre la mesa de discusión si los mensajes que por ahora mostramos en los museos están siendo lo suficientemente claros y sencillos para la comunidad no especializada, que es a quien -en teoría- se debe cada propuesta de exposición.

Considero preciso, tener presente que el experto debe ser un intermediario necesario para gestión de recursos en pro del patrimonio, pero no quien deba tener la última palabra en cuanto a la valoración de los recursos culturales, estos tienen que ser la resultante de un trabajo exhaustivo de la mano con la comunidad para que, según los cambios naturales en la sociedad, también sea continuamente que se hagan los ajustes necesarios, de tal manera, que los museos sin muros se conviertan en modelos permanentes, pero a la vez dinámicos de exposición.

Si bien es cierto, los museos no son las nuevas instituciones a cargo del patrimonio, una visión renovada y fuera de tradicional si lo es. Volver visibles los valores del patrimonio cultural, sin duda, requiere un esfuerzo adicional a la tarea que hasta hoy se viene haciendo en los museos. El reto, aunque parece un camino cuesta arriba, se debe plantear de manera que las propuestas se ajusten a las necesidades de cada medio y según cada situación real particular, procurando no desvincular a las comunidades del proceso ya que por definición, son ellas dueñas del patrimonio, de manera que finalmente deje de lado su actitud distraída, conformista y pasiva que tanto sigue empobreciendo la ya suficientemente deteriorada identidad cultural.

No por gusto sucede que, mientras las tareas de rescate y restauración urbanas (puramente intervenciones físicas-arquitectónicas) cuestan millones de dólares para su ejecución, el hecho de no tomar en cuenta los fenómenos socioculturales al alrededor y replantear nuevos usos sostenibles para los bienes en cuestión, hace que eventualmente vuelvan a deteriorarse al no existir interés alguno de protección proveniente desde el interior de la comunidad si no del grupo de expertos que considero importante intervenirlos .

Por ello, es preciso reiterar que se tiene que dejar de "intentar" trabajar de la mano con las diferentes comunidades que habitan un territorio para involucrarlas de hecho en los proyectos de resignificación urbana, pues es en la comunidad donde descansan los valores patrimoniales legítimos que dan sentido y significación a un lugar. 
He intentando recalcar en que no basta en delegar a los considerados expertos en patrimonio la tarea de la valoración cultural, sino someter a constante diálogo los puntos de vista con equipos interdisciplinarios y la comunidad, para proponer y ejecutar cualquier proyecto de resignificación.

Por ello, considero que la manera de presentar los resultados de dicho diálogo, perfectamente pueden adecuarse a propuestas atractivas, que de manera repensada hagan, por ejemplo, el nuevo discurso de museos un éxito como enlace entre comunidad-patrimonio-territorio producto de la construcción social creativa, y en la que se analicen a profundidad los verdaderos riesgos que amenazan el patrimonio y se evite seguir estigmatizando la interacción de los sujetos con las edificaciones (como único elemento patrimonial), cuando -como se ha evidenciado- se trata de una relación natural del hombre y el territorio, en el que dependiendo de la aproximación y del vinculo establecido entre ellos, el ser humano puede ser el mejor conservador o el peor destructor de su propio patrimonio.

\section{Referentes bibliográficos}

Ambrose, Timothy y Paine, Crispin. Museum Basics. The heritage: care-preservation-managment. Routledge 2da edición, New York. 2008.

Barroso, Julia. El discurso museográfico y la comunicación del Patrimonio. Roser Calaf coord., Comunicación educativa del patrimonio: Referentes, modelos y ejemplos. Madrid: Trea. 2004.

Fernández, Luis. Introducción a la nueva museología. Madrid:Alianza. 1999.

ICOMOS. Declaración sobre la preservación del Espíritu de lugar, Quebéc. 2008.

Hernández, Francisco. Didáctica e interpretación del patrimonio en Roser Calaf coord., Comunicación educativa del patrimonio: Referentes, modelos y ejemplos. Madrid: Trea. 2004.

Norberg -Schulz, Christian. Towards a phenomenology of architecture. New York. 1980.

Oriad, L. Contra la ciudad-museo: el papel del comercio callejero para la conservación del patrimonio urbano de los barrios tradicionales. En: Apuntes 24 (2): 288-299. 2011.

Vidart, D. El rico patrimonio de los orientales. Montevideo: Banda Oriental. Disponible En: www.unesco.org/culture/heritage/intangible/html_sp/index_sp-shtm. 2004. 


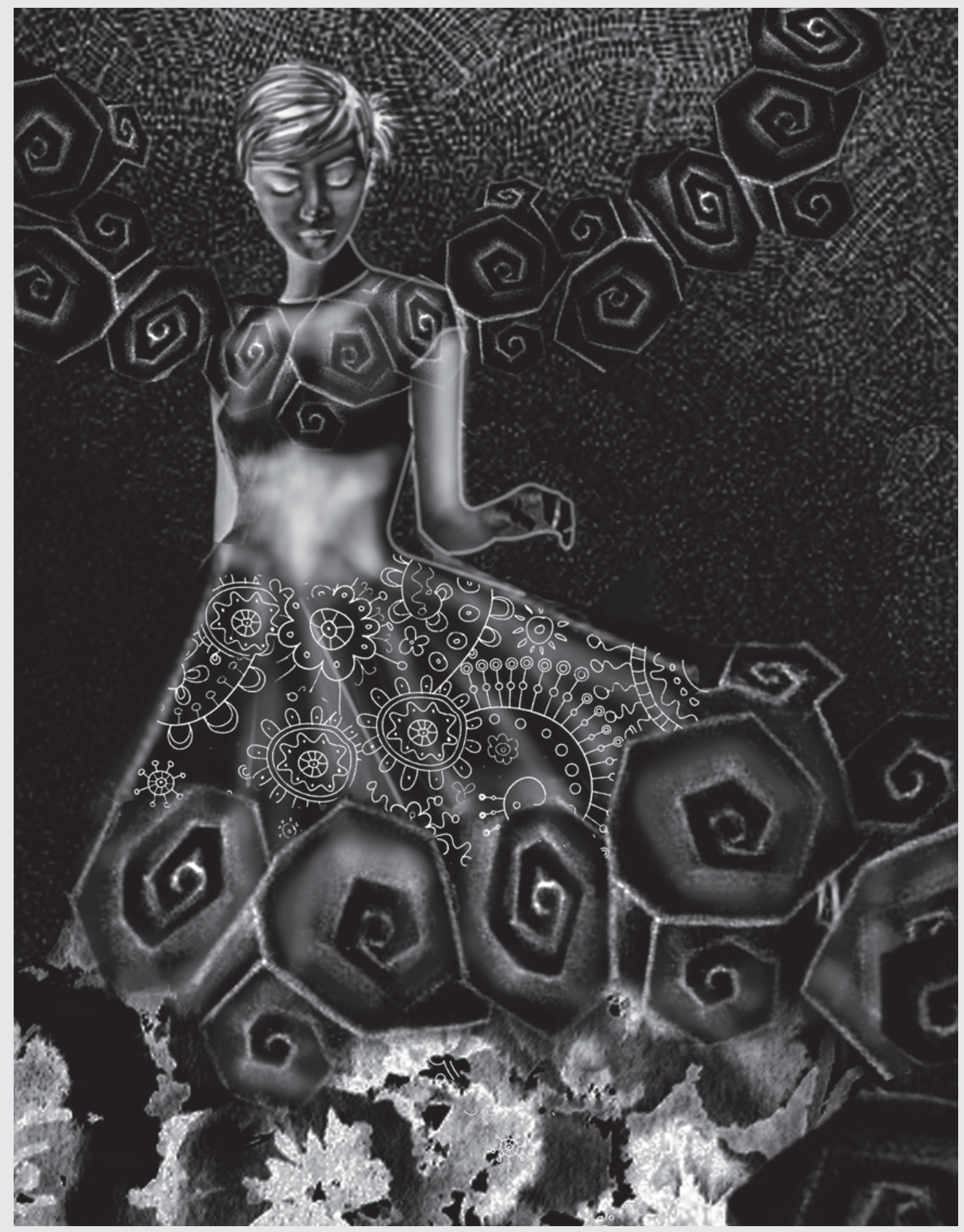

Ensueño. Técnica mixta, 8.5” x 11", Rita Araujo. 2013. 